\title{
Original article (short paper) \\ The burden of abdominal obesity with physical inactivity on health expenditure in Brazil
}

\author{
Jamile S. Codogno \\ Bruna C. Turi \\ São Paulo State University, Presidente Prudente, SP, Brazil \\ Flávia M. Sarti \\ University of São Paulo, São Paulo, SP, Brazil \\ Rômulo A. Fernandes \\ Henrique L. Monteiro \\ São Paulo State University, Presidente Prudente, SP, Brazil
}

\begin{abstract}
The purpose of this study was to analyze the association between the clustering of physical inactivity with abdominal obesity and public health care expenditure in Brazilian adults. The sample was composed of 963 patients of both genders, randomly selected in the Brazilian Public Health care System during 2010. Entire health care expenditures during the last year were computed and stratified into: medical consultations, medication dispensing, laboratory tests and overall expenditure. Waist circumference was used to diagnose abdominal obesity and physical activity was assessed by previously validated questionnaire. Sedentary and abdominally obese patients $\left(\mathrm{OR}=3.01\left[\mathrm{OR}_{95 \% \mathrm{CI}}=1.81-4.99\right]\right)$ had higher likelihood be inserted in the group of higher expenditures than only abdominally obese patients $(\mathrm{OR}=1.66$ $\left.\left[\mathrm{OR}_{95 \% \mathrm{CI}}=1.07-2.59\right]\right)$. There is a synergic effect between abdominal obesity and physical inactivity on overall health care expenditures.
\end{abstract}

Keywords: epidemiology, expenditures, physical activity, obesity

Resumo - "O peso da obesidade abdominal e inatividade física em despesas de saúde no Brasil." O objetivo deste estudo foi analisar a associação entre a agregação de inatividade física com a obesidade abdominal e despesas de saúde pública em adultos brasileiros. A amostra foi composta de 963 pacientes de ambos os sexos, selecionados aleatoriamente no Sistema Único de Saúde em 2010. Gastos com saúde durante o último ano foram computados e estratificados em: consultas médicas, distribuição de medicamentos, exames laboratoriais e gasto total. A circunferência da cintura foi usada para diagnosticar a obesidade abdominal e atividade física foi avaliada através de um questionário previamente validado. Pacientes sedentários e com obesidade abdominal $(\mathrm{OR}=3.01[\mathrm{IC} 95 \%=1.81-4.99])$ apresentaram maior probabilidade de ser inserido no grupo de despesas mais elevadas do que apenas os pacientes com obesidade abdominal $(\mathrm{OR}=1.66$ $[$ IC95\% $=1.07-2.59]$ ). Existe um efeito sinérgico entre a obesidade abdominal e sedentarismo em despesas totais de saúde.

Palavras-chave: epidemiologia, gastos, atividade física, obesidade

Resumen - "El peso de la obesidad abdominal y la inactividad física en el gasto en salud en Brasil." El objetivo de este estudio fue analizar la asociación entre la agregación de la inactividad física con la obesidad abdominal y el gasto público en salud en adultos brasileños. La muestra consistió en 963 pacientes de ambos sexos, seleccionados al azar en el Sistema de la Salud en 2010. El gasto en salud en el último año se calcula y se estratificó en: consultas médicas, medicamentos, exámenes de laboratorio y el gasto total. Circunferencia de la cintura se utiliza para diagnosticar la obesidad abdominal y la actividad física se evaluó mediante un cuestionario previamente validado. Pacientes sedentarios y con obesidad abdominal $(\mathrm{OR}=3,01[\mathrm{IC} 95 \%=1,81-4,99])$ tenían más probabilidades de ser incluido en el grupo de los mayores gastos que sólo los pacientes con obesidad abdominal ( $\mathrm{OR}=1,66$ [IC95\%=1,07-2,59]). Existe un efecto sinérgico entre la obesidad abdominal y la inactividad física en el gasto total en salud.

Palabras claves: epidemiología, gastos, actividad física, obesidad 


\section{Introduction}

A decrease in quality of life and an increase in years of life lost are outcomes which are significantly related to chronic diseases (Fontaine, Redden, Wang, Westfall, \& Alisson, 2003). Moreover, individuals diagnosed with chronic non-communicable diseases present increased public and private health care expenditure related to medical services, such as medicines, medical consultations and laboratory tests (Codogno, Fernandes, Sarti, Freitas Junior, \& Monteiro, 2011; Wolfenstetter, 2012).

The burden of disease caused by physical inactivity and obesity is well documented, especially in relation to the link between these two risk factors and the development of chronic non-communicable diseases. In fact, with regard to the harmful effects of excess body fat on human health, scientific literature has pointed out that the consequences of abdominal obesity are worse than general obesity (Huang, 2009). The biological pathways to explain these characteristics are linked to increased lipolysis and an increased release of adipokines into the bloodstream, which are common in the adiposity tissue located in the abdominal region (Huang, 2009).

However, predominantly in developing nations, the actual financial impact of abdominal obesity on the public health care system is not clear, mainly because most of studies use only markers of general obesity, such as body mass index (BMI). Between 2008 and 2010, overweight-related diseases resulted in a direct cost of US\$ 2.1 billion to the Brazilian public health care system (Bahia et al., 2012). Moreover, in 2007, overweight -related diseases constituted $6.8 \%$ and $9.3 \%$ of the total Brazilian public health care expenditure for men and women, respectively (Sichieri, do Nascimento, \& Coutinho, 2007).

The occurrence of obesity is inversely related to the practice of physical activity and, consequently, physical activity has been suggested as an important tool in decreasing public health care expenditure (Codogno et al., 2011; Codogno, Fernandes, \& Monteiro, 2012). Previous studies have reported that the implementation of community physical exercise programs could be beneficial for improving health indexes, such as quality-adjusted life years (Anokye et al. 2011). However, it is not clear if abdominal obesity and physical inactivity have either an independent or a dependent effect on health care expenditure in developing nations.

Therefore, the objective of this study was to analyze the association between clustering of physical inactivity with abdominal obesity and public health care expenditure in Brazilian adults.

\section{Methods}

\section{Sample}

The presented study had a cross-sectional design, and was carried out from August to December 2010 in Bauru city ( 300,000 inhabitants in the center of Sao Paulo state, the most industrialized Brazilian state). The sample was composed of patients from five basic health care units (BHU). In the Brazilian health care system, a BHU constitutes a medical unit designed for providing low complexity medical procedures and distribution of medicines. Each
BHU serves the population of a specific region of the city and offers the services of different health professionals (e.g. dentist, general practitioner, gynecologist, obstetrician, pediatrician and psychiatrist, among others) (Codogno et al., 2011). BHUs constitute the cornerstone of the Brazilian primary health care system and attend most of the population. Emergencies, surgical procedures and complex examinations are referred directly to the hospitals.

Sample size estimation identified the necessity of interviewing at least 774 patients (at the rate of physically active patients who had increased health care expenditure: $31.3 \%$ (Codogno et al., 2011), $Z=1.96$, an error of $4 \%$ and a design effect of $50 \%$ ). The city was stratified into five geographical regions (i.e., south, west, north, east and center) and the largest BHU from each geographical region was selected. The medical records of all patients attended to in the previous six months were compiled into a list and a minimum of 200 patients were randomly selected for interview from each BHU. After phone contact and data collection, the final sample size was composed of 963 patients. Prior to execution, the presented study was approved by the Ethical Research Group of the Sao Paulo State University (UNESP) from Bauru city, Brazil. All patients included in the analyzed sample signed a written consent form (Process: 1046/46/01/10).

\section{Outcome}

The procedures for estimating detailed health care expenditure per patient were described in a previous publication (Codogno et al., 2011). Briefly, the period of time considered for the assessment of expenditure was one year prior to the date of interview. Estimated expenditure included all items registered in the medical records for each patient (laboratory tests performed [performed in private laboratories that were paid for by the BHU]; medical consultations [e.g. dentist, gynecologist, obstetrician, general practitioner and psychiatrist, among others]; and medication dispensing). A specific standard table, including public health care reimbursement values, was provided by the BHU administrative offices and used in order to compute monetary values of laboratory tests and medical specialist consultations. Invoices obtained from the BHUs were used to compute the dosage and the market prices of medication used by patients. All expenditure was computed in the Brazilian currency (Real) and converted into US dollars using the average value of the dollar against the Brazilian currency during the 12 months prior to the interviews. In this study, health care expenditure was presented as: medical consultations, medication dispensing, laboratory tests and overall expenditure (sum of the three previous categories).

In the statistical analysis, health care expenditure was stratified into quartile and the highest quartile for all expenditure indicators $(\geq \mathrm{P} 75)$ was adopted as the standard outcome of the models.

\section{Abdominal obesity and physical inactivity}

Structured personal interviews and anthropometric measurements were carried out in a consulting room at each BHU by three trained researchers. Waist circumference (in $\mathrm{cm}$ ) was measured using a metallic tape according to Lohman (1988) 
and abdominal obesity was set at: men: $\geq 102 \mathrm{~cm}$ and women: $\geq 0.88 \mathrm{~cm}$ (Lean, Han, \& Morrison, 1995). Additonally, body weight (expressed in $\mathrm{kg}$ and measured by a digital scale) and height (expressed in $\mathrm{cm}$ and measured by a wall-mounted stadiometer) were assessed and used to calculate BMI (expressed in $\mathrm{kg} / \mathrm{m}^{2}$ ).

Physical activity level was estimated using the questionnaire developed by Baecke, Burema, and Frijters (1982), which takes into account three physical activity domains (occupational, sports and leisure and mobility). The patient's physical activity level is expressed by a score, which denotes the sum of all domains and is calculated by a specific equation (Baecke et al., 1982). The sample was split into quartiles according to the total physical activity score provided by the instrument (Codogno et al., 2011) and the lowest quartile was identified as physically inactive.

Finally, physical inactivity and abdominal obesity were clustered into a unique variable with four categories: (i) none ( $n=$ 201); (ii) abdominal obesity ( $n=525)$; (iii) physical inactivity ( $n=87)$; (iv) abdominal obesity and physical inactivity $(n=150)$.

\section{Covariates}

Five additional variables were documented and inserted in the multivariate model as potential confounders of the analyzed associations. They were: (i) chronological age (difference between birthday and interview day), (ii) sex (male or female), (iii) smoking habit (yes or no), (iv) formal education (in years) and (v) systolic and diastolic blood pressure (oscilometric device [in $\mathrm{mmHg}$ ).

\section{Statistical analysis}

There was non-parametric distribution in numerical variables. Therefore, the descriptive statistic was composed of median and interquartile range (IR) values. The Kruskal -Wallis' test was used to compare independent groups and the Mann-Whitney's test was used as a post-hoc test when necessary. Categorical variables were expressed as rates and compared using the chi-square test (Yates's correction was applied in $2 \times 2$ contingence tables). Significant associations detected by the chi-square test were further analyzed using binary logistic regression, which generated values of odds ratio (OR) and $95 \%$ confidence intervals $\left(\mathrm{OR}_{95 \% \mathrm{CI}}\right)$. In this multivariable model, health care expenditure was treated as a dependent variable and the cluster of abdominal obesity with physical inactivity was treated as an independent variable. After crude analysis in the multivariable model (Model-1), potential confounders were simultaneously inserted in the multivariable model (Model - 2), which generated adjusted values of $\mathrm{OR}$ and $\mathrm{OR}_{95 \% \mathrm{Cl}}$. In all the adjusted multivariable models, after inclusion of potential confounders, the Hosmer and Lemeshow's test was used to analyze the saturation of these models (non-significant result denotes an adequate adjust). All statistical analyzes were performed using the software BioEstat (release 5.0) and statistical significance was set at $p$-value $<.05$.

\section{Results}

The main components of the overall sample were women $(n=707[73.4 \%])$, older $[\geq 65$ years-old $(n=433,45.1 \%)]$, non -smokers $(n=835[86.7 \%])$, with an elevated rate of arterial hypertension $(n=740[76.8 \%])$ and abdominal obesity $(n=675$ $[70.1 \%])$. Abdominally obese and sedentary subjects were older than non-obese and physically active ones (Table 1). Moreover, the highest median values for medicine dispensing and overall expenditure were identified in the group composed of abdominally obese and sedentary subjects.

Table 1. General characteristics of the sample according to abdominal obesity and physical inactivity $(n=963 ;$ Brazil, 2010).

\begin{tabular}{|c|c|c|c|c|c|}
\hline Independent Variables & $\begin{array}{c}\text { None } \\
(n=201) \\
\text { Median (IR) }\end{array}$ & $\begin{array}{c}\text { Abdominal obesity } \\
(n=525) \\
\text { Median (IR) }\end{array}$ & $\begin{array}{c}\text { Physical Inactivity } \\
(n=87) \\
\text { Median (IR) }\end{array}$ & $\begin{array}{c}\text { Abdominal obesity and Physical } \\
\text { inactivity }(n=150) \\
\text { Median (IR) }\end{array}$ & $p$-value* \\
\hline \multicolumn{6}{|l|}{ Numerical } \\
\hline Age (years) & $62.1(12.3)$ & $63.1(12.4)$ & $67.9(17.1)^{\mathrm{a}, \mathrm{b}}$ & $67.9(17.6)^{\mathrm{a}, \mathrm{b}}$ & .001 \\
\hline BMI $\left(\mathrm{kg} / \mathrm{m}^{2}\right)$ & $24.5(3.6)$ & $30.9(6.1)^{\mathrm{a}}$ & $24.9(4.2)^{\mathrm{b}}$ & $30.6(6.4)^{\mathrm{a}, \mathrm{c}}$ & .001 \\
\hline $\mathrm{SBP}(\mathrm{mmHg})$ & $130(30)$ & $120(30)$ & $130(29)$ & $130(28)$ & .662 \\
\hline DBP $(\mathrm{mmHg})$ & $79(9)$ & $80(10)$ & $80(10)$ & $81(11)$ & .188 \\
\hline \multicolumn{6}{|l|}{ Expenditure (US\$) } \\
\hline Medical consultations & $36.9(25.8)$ & $42.1(27.8)^{\mathrm{a}}$ & $36.3(22.7)^{b}$ & $39.7(27.8)$ & .002 \\
\hline Laboratory tests & $5.1(21.2)$ & $11.4(25.2)$ & $8.1(23.3)$ & $1.98(23.4)$ & .134 \\
\hline Medicine use & $8.2(17.5)$ & $12.1(23.7)^{\mathrm{a}}$ & $12.4(22.2)^{\mathrm{a}}$ & $17.6(30.1)^{\mathrm{a}, \mathrm{b}, \mathrm{c}}$ & .001 \\
\hline Overall & $58.1(48.9)$ & $72.8(57.1)^{\mathrm{a}}$ & $66.7(56.8)$ & $78.6(73.5)^{\mathrm{a}}$ & .001 \\
\hline \multicolumn{6}{|l|}{ Categorical (\%) } \\
\hline Smoking habit & 16.5 & 11.1 & 17.1 & 19.1 & .202 \\
\hline Sex (female) & 61.2 & 91.2 & 18.4 & 57.3 & .001 \\
\hline Formal education ( $\geq 8 \mathrm{yrs})$ & 16.4 & 13.5 & 14.9 & 17.3 & .226 \\
\hline
\end{tabular}

*= statistical significance provided by the Kruskal-Wallis test; $\mathrm{a}=$ Mann-Whitney test with $\mathrm{p}$-value $<.05$ compared to none; $\mathrm{b}=$ Mann-Whitney test with $p$-value $<.05$ compared to abdominal obesity; $\mathrm{c}=$ Mann-Whitney test with $p$-value $<.05$ compared to physical inactivity; $\mathrm{SBP}=$ systolic blood pressure; $\mathrm{DBP}=$ diastolic blood pressure; $\mathrm{BMI}=$ body mass index. 
Table 2. Association between higher health care expenditure, abdominal obesity and physical inactivity $(n=963 ;$ Brazil, 2010).

\begin{tabular}{|c|c|c|c|c|c|}
\hline Independent Variables & $\begin{array}{l}\text { None } \\
n(\%)\end{array}$ & $\begin{array}{c}\text { Abdominal obesity } \\
n(\%)\end{array}$ & $\begin{array}{c}\text { Physical inactivity } \\
n(\%)\end{array}$ & $\begin{array}{c}\text { Abdominal obesity and } \\
\text { Physical inactivity } \\
n(\%)\end{array}$ & $p$-value* \\
\hline \multicolumn{6}{|l|}{ Expenditure ( $\geq$ P75) } \\
\hline Medical consultations & $39(19.4)$ & $149(28.4)$ & $18(20.7)$ & $36(24)$ & .737 \\
\hline Laboratory tests & $39(19.4)$ & $146(27.8)$ & $21(24.1)$ & $35(23.3)$ & .667 \\
\hline Medicine & $34(16.9)$ & $130(24.8)$ & $21(24.1)$ & $56(37.3)$ & .001 \\
\hline Overall & $29(14.4)$ & $143(27.2)$ & $19(21.8)$ & $50(33.3)$ & .001 \\
\hline
\end{tabular}

*= statistical significance provided by chi-square test.

A

\section{Medication Expenditures}

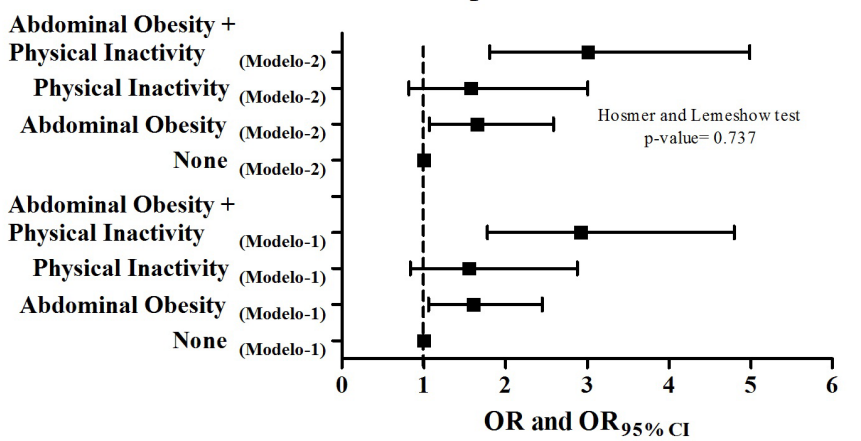

Model-1: crude

Model-2: adjuted by sex, age, basic healthcare unit, schooling, smoking habit, systolic and diastolic blood pressure
$\mathrm{B}$

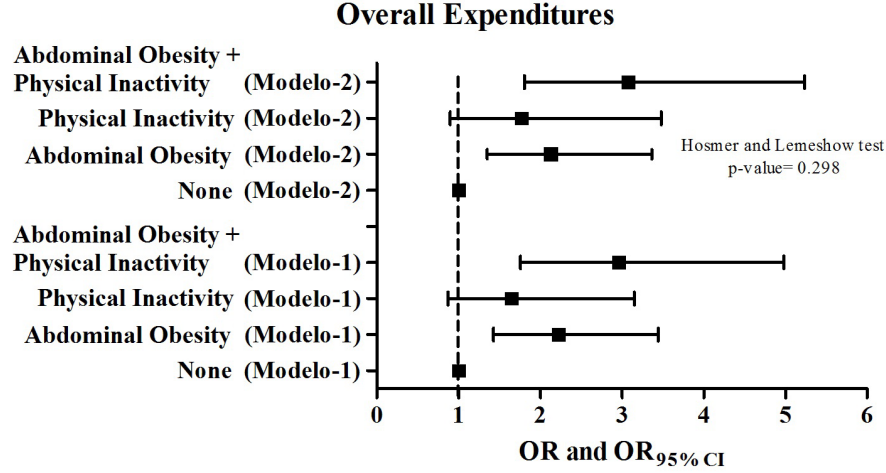

Model-1: crude

Model-2: adjuted by sex, age, basic healthcare unit, schooling, smoking habit, systolic and diastolic blood pressure

Figure 1. Multivariable association between higher health care expenditure and clustering of abdominal obesity and physical inactivity $(n=963$; Brazil, 2010).

In the analyzed sample, the overall expenditure was approximately US\$ $85,947.56$ per year and medication dispensing represented $35.2 \%$ (US\$ 30,292.99) of the overall expenditure. Medical consultations and laboratory tests represented $46.9 \%$ (US\$ 40,384.44) and 17.7\% (US\$ 15,270.13) of the overall expenditure, respectively. The physical activity score was negatively related to medicine dispensing $(\mathrm{rho}=-0.13 ; p$-value $=.001)$ and overall expenditure $(\mathrm{rho}=-0.06 ; p$-value $=.041)$. On the other hand, waist circumference was positively related to medical consultation $(\mathrm{rho}=0.09 ; p$-value $=.004)$, medicine dispensing $(\mathrm{rho}=0.25 ; p$-value $=.001)$ and overall expenditure $(\mathrm{rho}=0.19 ;$ $p$-value $=.001)$. Similarly, BMI was positively related to medical consultation $(\mathrm{rho}=0.10 ; p$-value $=.001)$, medicine dispensing $(\mathrm{rho}=0.20 ; p$-value $=.001)$ and overall expenditure $(\mathrm{rho}=0.17 ; p$ value $=.001)$. The physical activity score and waist circumference were negatively related to each other $(\mathrm{rho}=-0.14$; $p$-value $=.001)$.

The abdominal obesity and physical inactivity cluster was associated with higher expenditure relating to medicine dispensing $(p$-value $=.001)$ and overall expenditure $(p$-value $=.001)$. Whereas expenditure related to medical consultation $(p$-value= $.737)$ and laboratory tests $(p$-value $=.667)$ were not $($ Table 2$)$.

The binary logistic regression model identified that, independent of other potential confounders, being either abdominally obese $\left(\mathrm{OR}=1.66\left[\mathrm{OR}_{95 \% \mathrm{CI}}=1.07-2.59\right]\right)$ or abdominally obese and sedentary $\left(\mathrm{OR}=3.01\left[\mathrm{OR}_{95 \% \mathrm{CI}}=1.81-4.99\right]\right)$ were associated with an increased likelihood of being inserted in the highest health care expenditure group with regard to medicine dispensing (Figure 1, Panel A). Similarly, the same pattern of association was observed for overall expenditure: abdominally obese $\left(\mathrm{OR}=2.13\left[\mathrm{OR}_{95 \% \mathrm{CI}}=1.35-3.37\right]\right)$ and abdominally obese and sedentary $\left(\mathrm{OR}=3.08\left[\mathrm{OR}_{95 \% \mathrm{CI}}=1.81-5.23\right]\right)($ Figure $1, \mathrm{~Pa}-$ nel B). In all multivariate analyzes, after inclusion of potential confounders, there was no saturation of the models (Hosmer and Lemeshow test with $p$-value $>.05$ ).

\section{Discussion}

The presented survey aimed to analyze the association between clustering of abdominal obesity with physical activity and health expenditure in Brazilian users of the public health care system.

It is very difficult to compare the prevalence of abdominal obesity in adults, because BMI is the main anthropometric tool used worldwide and, thus, there is an absence of epidemiological surveys presenting data of abdominal obesity (mainly in developing nations). In fact, the prevalence of general obesity $\left(\mathrm{BMI} \geq 30 \mathrm{~kg} / \mathrm{m}^{2}\right)$ in $2007-2008$ was higher than $30 \%(33.8 \%$ [95\%CI: $31.6 \%$ - 36\%]) in the USA (Flegal, Carroll, Ogden, \& 
Curtin, 2010), whereas in Brazil an increased trend in general obesity has been identified in recent years (Gigante, França, Sardinha, Iser, \& Meléndez, 2011).

In the present study, the prevalence of abdominal obesity was $70.1 \%$, which is higher than the $46 \%$ and $44 \%$ observed among the general Brazilian adult population from the northeast and south regions, respectively (de Sousa, Nahas, Silva, Del Duca, \& Peres, 2011; Veloso \& Silva, 2010). The higher prevalence of abdominal obesity identified in this study is similar to a previous study with patients $(63.5 \%)$ from the Brazilian public health system (Girotto, Andrade, Cabrera, \& Matsuo, 2013) and could be justified by the fact that this specific sample was composed of adults with a previous disease, which could have been related to the presence of abdominal obesity (Sichieri et al., 2007). Moreover, the increased prevalence of obesity in this sample could be justified by the inclusion criteria being based on older individuals (Flegal et al., 2010; Qin et al., 2013) and containing a high number of women, who are affected by postmenopausal effects that lead to gain of weight (Flegal et al., 2010; Huang, 2009). Therefore, the presented data corroborate to previous findings using general obesity and identifies that abdominal obesity also constitutes a public health concern in the Brazilian adult population, which is significantly related to an increased demand for health services.

Independent of other potential confounders, those patients with abdominal obesity in addition to those with abdominal obesity plus sedentary behavior presented increased health care expenditure. The positive association between general obesity and increased health care costs has been identified in previous studies (Bahia et al., 2012). In a cohort study, Wolfenstetter (2012) identified that overweight people who became obese during the follow up had higher direct and indirect health care costs than individuals who maintained their body weight, even whilst still being overweight. Moreover, obese people presented higher costs than those who were normal weight or overweight.

General obesity has been positively related to the development of a wide range of diseases (Van Gaal, Mertens, \& De Blo$\mathrm{ck}, 2006)$ and this fact could support the increased expenditure related to medicine dispensing observed in our study (BMI was also related to higer expenditures). In fact, the harmful effect of general obesity on human health could be explained, at least in part, by abdominal obesity, because general and abdominal obesity are strongly linked outcomes. Among adults with a $\mathrm{BMI} \geq 30 \mathrm{~kg} / \mathrm{m}^{2}$ there is a high prevalence of abdominal obesity (80.5\%) (Flegal et al., 2010). Similarly, in this specific sample $98.7 \%$ of the obese patients had also abdominal obesity. It is well documented that abdominal adipose tissue releases a large variety of adipokines into the bloodstream, which are related to the inflammatory process in the human organism and, hence, the development of diseases widely observed in adults (type 2 diabetes mellitus, arterial hypertension and dyslipidemia) have been linked to abdominal obesity (Huang, 2009; Mlinar, Marc, Janez, \& Pfeifer, 2007).

In the patients of the present study, physical activity was inversely related to abdominal obesity and variables related to health care expenditure. Similarly, in diabetic patients, physical activity is inversely associated with expenditure on medication for the treatment of diseases other than diabetes (mainly arterial hypertension, dyslipidemia, osteoporosis and hypothyroidism) and medical consultations (Codogno et al., 2011). It is well documented that physical activity is related to the prevention of many diseases such as obesity, dyslipidemia and hypertension (Fernandes et al., 2011; Fernandes \& Zanesco, 2010), as well early-mortality (Moore et al., 2012). In the analyzed survey, sedentary patients did not have higher expenditure than non-abdominally obese and physically active ones. Apparently, in the analyzed outcome (health care expenditures) the protective effect of physical activity practice is mainly due to the negative relationship between physical activity and adiposity.

On the other hand, although physical inactivity had a nonsignificant burden on health care expenditure in the analyzed phenomenon, it is noteworthy that the clustering of abdominal obesity with physical inactivity had a higher effect on health expenditure than abdominal obesity alone. Several possible explanations for this synergic effect are based on the types of sedentary behaviors. Physically inactive people spend more time engaged in sedentary behaviors, such as watching TV and using computer. Sedentary behaviors have been associated with mortality independent of physical activity practice (Koster et al., 2012). In fact, these kind of behaviors have been associated with adoption of other risk behaviors, such as a smoking habit, poor quality of food intake and skipping meals, which are related both to each other and to other risk behaviors (Fernandes et al., 2011b; Freitas Junior et al., 2012; Larson, Story, Perry, Neumark-Sztainer, \& Hannan, 2007; Nagaya, Yoshida, Takahashi, \& Kawai, 2007). Therefore, the higher harmful effect of the variables clustering could be supported by the sum of these unhealthy behaviors with the metabolic and cardiovascular complications linked to obesity (Ignarro, Balestrieri, \& Napoli, 2007).

The limitations of this study should be highlighted. Initially, the effect of physical inactivity and abdominal obesity on health care expenditure could have been underestimated in these patients, because there were no data related to hospitalizations and absenteeism. However, this kind of expenditure is not related to the BHUs, which are responsible for lower complexity medical procedures, medical consultations and medicine dispensing. Moreover, the cross-sectional design should be considered, since cohort studies and randomized clinical trials are still necessary to describe clearly the actual burden of abdominal obesity and physical inactivity on public health care expenditures.

In summary, it is possible to conclude that there is a synergic effect between abdominal obesity and physical inactivity on health care expenditure related to total health care expenditure, mainly due to the effect of medication expenditure. Medication costs represented approximately $35 \%$ of the overall expenditure of these patients and, therefore, the promotion of higher physical activity practice (and, in turn, the decrease of adiposity) could be responsible for a substantial reduction in health care expenditure in the Brazilian public health care system. 


\section{References}

Anokye, N.K., Trueman, P., Green, C., Pavey, T.G., Hillsdon, M., \& Taylor, R.S. (2011). The cost-effectiveness of exercise referral schemes. BMC Public Health, 11, 954. doi: 10.1186/1471-2458-11-954

Baecke, J.A., Burema, J., \& Frijters, J.E. (1982). A short questionnaire for the measurement of habitual physical activity in epidemiological studies. American Journal of Clinical Nutrition, 36, 936-942. http://ajcn.nutrition.org/content/36/5/936.long

Bahia, L., Coutinho, E.S., Barufaldi, L.A., Abreu, G.A., Malhão, T.A., de Souza, C.P., \& Araujo, D.V. (2012). The costs of overweight and obesity-related diseases in the Brazilian public health system: cross-sectional study. BMC Public Health, 12, 440. doi: 10.1186/1471-2458-12-440

Codogno, J.S., Fernandes, R.A., \& Monteiro, H.L. (2012). Physical activity and healthcare cost of type 2 diabetic patients seen at basic units of healthcare. Arquivos Brasileiros de Endocrinologia e Metabologia, 56, 6-11. doi: 10.1590/S0004-27302012000100002

Codogno, J.S., Fernandes, R.A., Sarti, F.M., Freitas Júnior, I.F., \& Monteiro, H.L. (2011). The burden of physical activity on type 2 diabetes public healthcare expenditures among adults: a retrospective study. BMC Public Health, 11, 275. doi: 10.1186/1471-2458-11-275

de Sousa, T.F., Nahas, M.V., Silva, D.A., Del Duca, G.F., \& Peres, M.A. (2011). Factors associated with central obesity in adults from Florianópolis, Santa Catarina: a population based-study. Revista Brasileira de Epidemiologia, 14, 296-309. doi: 10.1590/S1415790X2011000200011

Fernandes, R.A., Christofaro, D.G., Casonatto, J., Codogno, J.S., Rodrigues, E.Q., Cardoso, M.L., ... Zanesco, A. (2011). Prevalence of dyslipidemia in individuals physically active during childhood, adolescence and adult age. Arquivos Brasileiros de Cardiologia, 97, 317-323. doi: 10.1590/S0066-782X2011005000083

Fernandes, R.A., Christofaro, D.G., Casonatto, J., Kawaguti, S.S., Ronque, E.R., Cardoso, J.R., ... Oliveira, A.R. (2011)b. Crosssectional association between healthy and unhealthy food habits and leisure physical activity in adolescents. Jornal de Pediatria. (Rio J), 87, 252-256. doi:10.2223/JPED.2093

Fernandes, R.A., \& Zanesco, A. (2010). Early physical activity promotes lower prevalence of chronic diseases in adulthood. Hypertension Research, 33, 926-931. doi: 10.1038/hr.2010.106

Flegal, K.M., Carroll, M.D., Ogden, C.L., \& Curtin, L.R. (2010). Prevalence and trends in obesity among US adults, 1999-2008. Journal of the American Medical Association, 303, 235-241. doi: 10.1001/jama.2009.2014

Fontaine, K.R., Redden, D.T., Wang, C., Westfall, A.O., \& Allison D,B. (2003). Years of life lost due to obesity. Journal of the American Medical Association, 289, 187-193. doi:10.1001/jama.289.2.187

Freitas Junior, I.F., Christofaro, D.G., Codogno, J.S., Monteiro, P.A., Silveira, L.S., \& Fernandes, R.A. (2012). The association between skipping breakfast and biochemical variables in sedentary obese children. The Journal of Pediatrics, 161, 871-874. doi: 10.1016/j.jpeds.2012.04.055

Gigante, D.P., de França, G.V., Sardinha, L.M., Iser, B.P., \& Meléndez, G.V. (2011). Temporal variation in the prevalence of weight and obesity excess in adults: Brazil, 2006 to 2009. Revista Brasileira de Epidemiologia, 14, 157s-165s. doi: 10.1590/S1415790X2011000500016

Girotto, E., Andrade, S.M., Cabrera, M.A., \& Matsuo, T. (2013). Adherence to pharmacological and non-pharmacological treatment for arterial hypertension and associated factors in primary care. Ciencia \& Saude Coletiva, 18, 1763-1772. doi: 10.1590/S1413-81232013000600027

Huang, P.L. (2009). eNOS, metabolic syndrome and cardiovascular disease. Trends in Endocrinology \& Metabolism, 20, 295-302. doi: 10.1016/j.tem.2009.03.005
Ignarro, L.J., Balestrieri, M.L., \& Napoli, C. (2007). Nutrition, physical activity, and cardiovascular disease: an update. Cardiovascular Research, 73, 326-340. doi: 10.1016/j.cardiores.2006.06.030

Koster, A., Caserotti, P., Patel, K.V., Matthews, C.E., Berrigan, D., Van Domelen, D.R., ... Harris, T.B. (2012). Association of sedentary time with mortality independent of moderate to vigorous physical activity. Public Library of Science One, 7, e37696. doi: 10.1371/ journal.pone.0037696

Larson, N.I., Story, M., Perry, C.L., Neumark-Sztainer, D., \& Hannan, P.J. (2007). Are diet and physical activity patterns related to cigarette smoking in adolescents? Findings from Project EAT. Preventive Chronic. Diseases, 4, A51. http://www.cdc.gov/pcd/ issues/2007/jul/06 0053.htm.

Lean, M.E., Han, T.S., \& Morrison, C.E. (1995). Waist circumference as a measure for indicating need for weight management. British Medical Journal, 311, 158-161. doi: 10.1136/bmj.311.6998.158

Lohman, T.G. (1988). Anthropometric Standardization Reference Manual. Champaign: Human Kinetics Books.

Mlinar, B., Marc, J., Janez, A., \& Pfeifer, M. (2007). Molecular mechanisms of insulin resistance and associated diseases. Clinica Chimica Acta, 375, 20-35. doi: 10.1016/j.cca.2006.07.005

Moore, S.C., Patel, A.V., Matthews, C.E., Berrington de Gonzalez, A., Park, Y., ... Lee, I.M. (2012). Leisure Time Physical Activity of Moderate to Vigorous Intensity and Mortality: A Large Pooled Cohort Analysis. Public Library of Science Med, 9, e1001335. doi: 10.1371/journal.pmed.1001335

Nagaya, T., Yoshida, H., Takahashi, H., \& Kawai, M. (2007). Cigarette smoking weakens exercise habit in healthy men. Nicotine \&Tobbaco Research, 9, 1027-1032. doi: 10.1080/14622200701591575

Qin, X., Zhang, Y., Cai, Y., He, M., Sun, L., Fu, J., ... Huo, Y. (2013). Prevalence of obesity, abdominal obesity and associated factors in hypertensive adults aged 45-75 years. Clinical Nutrition, 32, 361-367. doi: 10.1016/j.clnu.2012.08.005

Sichieri, R., do Nascimento, S., \& Coutinho, W. (2007). The burden of hospitalization due to overweight and obesity in Brazil. $\mathrm{Ca}$ dernos de Saude Publica, 23, 1721-1727. doi: 10.1590/S0102311X2007000700025

Van Gaal, L.F., Mertens, I.L., \& De Block, C.E. (2006). Mechanisms linking obesity with cardiovascular disease. Nature, 444, 875-880. doi:10.1038/nature05487

Veloso, H.J., \& da Silva, A,A. (2010). Prevalence and factors associated with abdominal obesity and excess weight among adults from Maranhão, Brazil. Revista Brasileira de Epidemiologia, 13, 400-412. doi: 10.1590/S1415-790X2010000300004

Wolfenstetter, S.B. (2012). Future direct and indirect costs of obesity and the influence of gaining weight: results from the MONICA/ KORA cohort studies, 1995-2005.Economics \& Human Biology, 10, 127-138. doi: 10.1016/j.ehb.2011.08.008

\section{Authors'note}

Jamile S. Codogno and Rômulo A. Fernandes are affiliated with the Laboratory of InVestigation in Exercise (LIVE), Department of Physical Education, and Graduate Program in Movement's Sciences, Institute of Bioscience, São Paulo State University (UNESP), Rio Claro, Brazil.

Bruna C. Turi and Henrique L. Monteiro are affiliated with the Graduate Program in Movement's Sciences, Institute of Bioscience, São Paulo State University (UNESP), Rio Claro, Brazil.

Flávia M. Sarti is affilaited with the School of Arts, Sciences and Humanities, University of São Paulo (USP), São Paulo, Brazil. 


\section{Corresponding author}

Dr. Jamile Sanches Codogno

Universidade Estadual Paulista (UNESP), Faculdade de Ciências e Tecnologia.

Rua Roberto Simonsen, 305, Bloco III, Sala 04.

Presidente Prudente, SP, 19060-900 Brazil.

E-mail: jamile@fct.unesp.br

\section{Conflict of interest}

All authors declare that there is no conflict of interest.

Manuscript submitted on March 31, 2014

Manuscript accepted on December 16, 2014

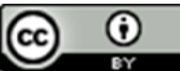

Motriz. The Journal of Physical Education. UNESP. Rio Claro, SP, Brazil - eISSN: 1980-6574 - under a license Creative Commons - Version 3.0 